Bericht: Specielle analyt. Methoden. 1. Auf Jiebensmittel etc. bez. 113

IV. Specielle analytische Methoden.

1. Auf Lebensmittel, Gesundheitspflege, Handel, Industric und Landwirthschaft bezügliche.

$$
\text { Von }
$$

\title{
L. Grünhut.
}

Zolltechnische Unterscheidung zwischen Talg und Stearinmasse. Nach der älteren amtlichen Instruction für die zolltechnische Unterscheidung des Talges und der Kerzenstoffe ${ }^{1}$ ) sind Fette, deren Gehalt an freier Fettsäure $25 \%$ übersteigt, als Stearinmasse zu bezeichnen und entsprechend zu verzollen ${ }^{2}$ ). F. Gantter ${ }^{3}$ ) theilt einen concreten Fall mit, in dem für einen stark ranzigen Talg von $28,9 \%$ freien Fettsäuren die Verzollung als Stearinmasse beansprucht wurde. Durch quantitative Bestimmung des Glycerins konnte der Nachweis erbracht werden, dass nur ein ranzig gewordenes Neutralfett vorlag und nicht die Mischung eines solchen mit Stearinsäure. Es ergab sich folgende nähere Zusammensetzung.

In Alkohol löslicher Antheil

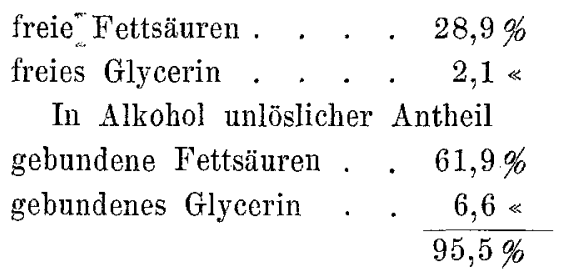

Die Glycerinbestimmung geschah nach des Verfassers gasvolumetrischem Verfahren ${ }^{4}$ ).

Der Zündsatz für Zündhütchen besteht meistens aus Käliumchlorat, Antimonsulfür und Knallquecksilber. Ein einfaches Verfahren zur Analyse solcher Mischungen gründen F. W. Jones und F. A. Will cox ${ }^{5}$ ) auf die von ihnen entdeckte Löslichkeit des Knallquecksilbers in Aceton,

1) Diese Zeitschrift 31, A. V. u. E. 27 (1892).

2) Nach der neueren Anweisung (diese Zeitschrift 35, A. V. u. E. 4) liegt der Grenzwerth bei $30 \%$ freien Fettsänren.

3) Forschungsberichte über Lebensmittel etc. 2, 113.

4) Diese Zeitschrift 34, 421 (1896).

5) Chem. News 74, 283. 